\title{
Developments in superplasticity over the last three decades with emphasis on research in Ufa
}

\author{
Terence G. Langdon ${ }^{\dagger}$ \\ †langdon@soton.ac.uk
}

Materials Research Group, Department of Mechanical Engineering, University of Southampton, Southampton SO171BJ, U. K.

Superplasticity refers to the ability of some materials to exhibit exceptionally high elongations when pulled in tension. This phenomenon forms the background for the use of superplastic forming in which complex curved parts may be fabricated through relatively simple forming operations. At the present time, this type of forming is important in manufacturing products for a wide range of industrial applications. An important development in this field occurred in 1985 when Professor Oscar Kaibyshev established the Institute for Metals Superplasticity Problems (IMSP) under the auspices of the Russian Academy of Sciences in Ufa in the Ural Mountains region of Russia. At that time, this institute was, and remains to this day, the first and only institute devoted exclusively to the development of research in superplasticity. In practice, the establishment of this institute came at an appropriate time because it marked the beginning of the availability of new and sophisticated tools which permitted detailed microstructural observations which surpassed the techniques available in earlier decades. In this special issue of the journal devoted to "Superplasticity and Related Phenomena" it is appropriate, therefore, to examine some of the developments in superplasticity that have occurred over the last three decades with an emphasis on research conducted by scientists from Ufa.

Keywords: ductility, grain boundary sliding, microstructure, superplasticity, ultrafine grains.

\section{Introduction}

When metals are pulled in tension, they generally break after pulling out to only relatively small elongations. Nevertheless, it was reported in several early publications, dating back to the early part of the last century, that it may be possible under some conditions to achieve quite high elongations of the order of two or three hundreds of per cent. It is now known that very large elongations may be achieved in the process known as superplasticity in which metals pull out in tension with little or no necking and finally exhibit failure elongations that are in excess of $400 \%$ [1]. The first direct example of true superplasticity was presented in the research of Pearson [2] conducted in England in the 1930s. In this work, it was reported that a two-phase Bi-Sn eutectic alloy exhibited an elongation of $1950 \%$ in tensile testing and this example is shown in Fig. 1 where the sample is coiled to facilitate easy photography.

Unfortunately, the remarkable results achieved by Pearson [2] in England were essentially overlooked in western countries but instead they led to very extensive experiments on superplasticity conducted by a number of prominent researchers in the Soviet Union. This research only became known in the west at a much later time in the 1960s as a result of the publication of a comprehensive review of the many reports then available describing this superplastic behavior [3]. This latter review effectively established superplasticity as a viable scientific area of considerable interest and industrial potential, especially because of the development of the superplastic forming industry for the fabrication of curved and complex parts for a range of commercial products [4]. Thereafter, an exceptional elongation of $4850 \%$ was achieved in the Pb-Sn eutectic alloy [5] and reported in the Guinness Book of World Records [6] and later an even higher elongation of $7550 \%$ was attained in the same alloy when testing at $413 \mathrm{~K}$ with a grain size of $11.6 \mu \mathrm{m}$ as shown in Fig. 2 [7].

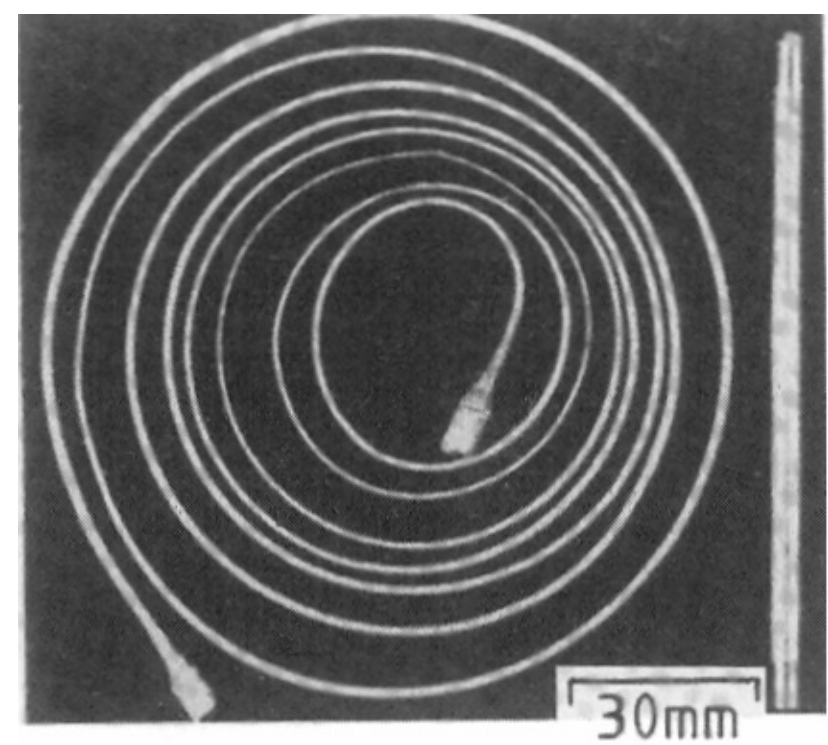

Fig. 1. A Bi-Sn alloy showing an elongation of $1950 \%$ reported in 1934 by Pearson [2]. 


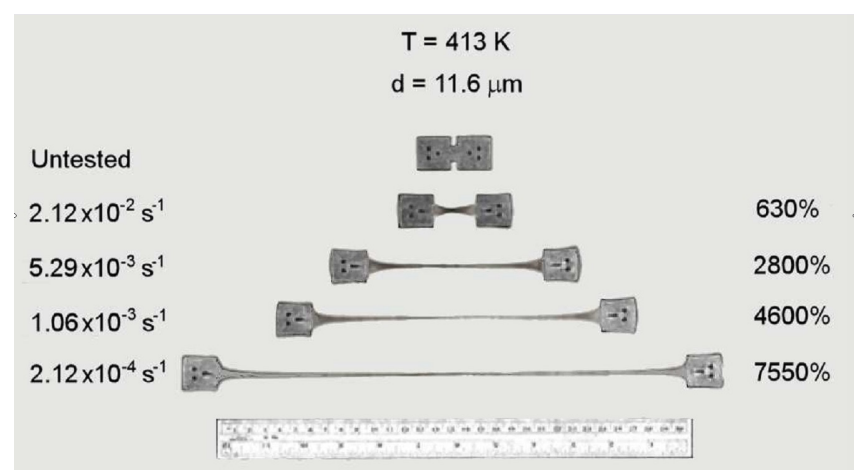

Fig. 2. An example of an elongation of $7550 \%$ in a $\mathrm{Pb}-\mathrm{Sn}$ eutectic alloy pulled to failure at $413 \mathrm{~K}$ using an initial strain rate of $2.12 \times 10^{-4} \mathrm{~s}^{-1}[7]$.

\section{Establishing a superplasticity institute in Ufa}

From the 1970s onwards many laboratories around the world began investigating all aspects of superplasticity for a very wide range of metals and also some ceramics. A very important development in this period occurred in 1985 when Professor Oscar Kaibyshev established the Institute for Metals Superplasticity Problems (IMSP) in the city of Ufa in the Ural mountains to the east of Moscow. This institute was established under the auspices of the Russian Academy of Sciences and it was at the time, and remains to this day, the only institute in the world devoted exclusively to research in the areas of superplastic flow and superplastic forming. The institute is contained in an impressive large building in the city of Ufa and a photograph of the institute is shown in Fig. 3 [8].

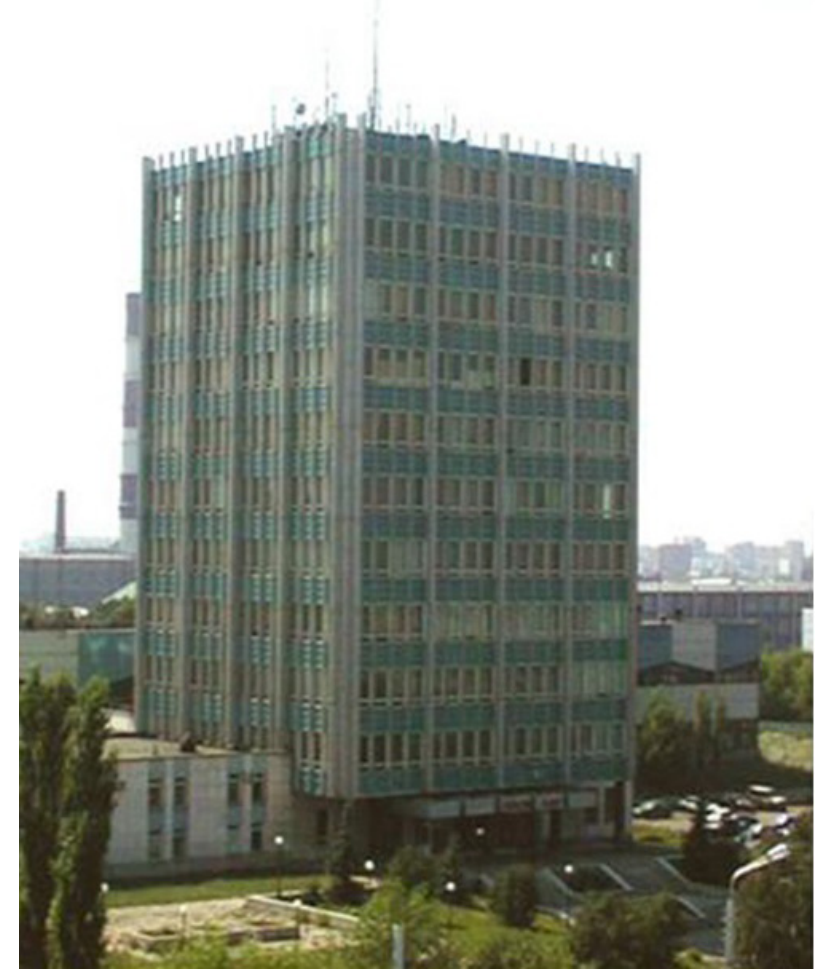

Fig. 3. (Color online) The IMSP building in Ufa used for research on all aspects of superplastic flow and superplastic forming [8].

\section{Early research at IMSP}

The creation of this new institute in Ufa gave a remarkable impetus to developments in superplasticity and these developments, and extensive cutting-edge research, has continued to the present day. An important early proposal was that materials may contain non-equilibrium grain boundaries in which the boundaries contain not only the intrinsic dislocations that delineate the boundary misorientations but also arrays of extrinsic dislocations that control the boundary properties [9].

It was well established in many early experiments that superplastic flow requires both a very small grain size typically smaller than $\sim 10 \mu \mathrm{m}$ and, because it is a diffusioncontrolled process, a high testing temperature typically above $\sim 0.5 T_{\mathrm{m}}$ where $T_{\mathrm{m}}$ is the absolute melting temperature of the material [10]. In practice, thermo-mechanical processing was used to attain these very small grain sizes.

Nevertheless, a fundamental problem with thermomechanical processing was the general inability to achieve grain sizes smaller than about 2 or $3 \mu \mathrm{m}$. Accordingly, a very important early development in research at IMSP was the demonstration that the processing of an $\mathrm{Al}-4 \% \mathrm{Cu}-0.5 \% \mathrm{Zr}$ alloy by shear under pressure, the procedure now known as high-pressure torsion, was capable of producing an exceptionally small grain size of only $0.3 \mu \mathrm{m}$ and this gave an opportunity for achieving not only superplastic flow but also superplasticity at unusually low temperatures [11]. This report had a major influence on research on superplasticity and on ultrafine-grained materials with the result that this type of research is now being undertaken at a very wide range of laboratories around the world.

The processing of metals by high-pressure torsion (HPT) refers to the situation where a sample, generally in the form of a thin disk, is subjected to an applied pressure and then concurrent torsional straining. This processing procedure is now established as a major tool in the fabrication of metals with exceptionally small grain sizes and it is one of a number of procedures in which severe plastic deformation (SPD) is used to impart a very high strain with little or no change in the overall dimensions of the test sample. Another very important SPD processing method is equal-channel angular pressing (ECAP) in which the sample, in the form of a rod or bar, is pressed through a die constrained within a channel which is bent through a sharp angle near the centre of the die. Both of these procedures were used extensively at IMSP in conducting research on many different materials. These investigations led to many achievements in research in Ufa and a brief tabulation of some of these achievements was presented earlier [12].

An important characteristic of the Ufa research was the publication of detailed reports describing the results and presenting detailed interpretations. The researchers at IMSP also contributed extensively to the production of major review articles which have received large numbers of citations. For example, a major review of SPD processing by Valiev et al. [13] was published in 2000 and it is now the \#2 all-time most cited paper to appear in Progress in Materials Science with 4684 citations as of mid-September 2018, a paper by Valiev and Langdon [14] on ECAP is now the \#4 all- 
time most cited paper in Progress in Materials Science with 2574 citations and a paper by Zhilyaev and Langdon [15] on HPT is now the \#11 all-time most cited paper to appear in Progress in Materials Science with 1502 citations. This means that researchers from Ufa account for three out of 20 of the all-time most cited papers in Progress in Materials Science and this is a remarkable achievement.

There have been also important contributions to the scientific literature through membership of the International NanoSPD Steering Committee where Professor Ruslan Valiev is the committee chairman. A publication by the members of this committee in 2006 provided rigorous definitions of SPD and ultrafine-grained materials and this report is now the \#1 all-time most cited paper to appear in JOM with 973 citations [16]. An invited report published ten years later as a follow-on description of new developments in the SPD processing of materials with ultrafine grain sizes is now ranked as the \#1 most cited paper to appear in JOM in 2016 with 62 citations [17].

\section{Developments in research on superplasticity}

In superplastic flow the production of smaller grains is anticipated to lead to the occurrence of superplastic elongations at faster strain rates. This means that there is a potential for achieving high strain rate superplasticity which refers to the occurrence of superplastic elongations at strain rates at and above $10^{-2} \mathrm{~s}^{-1}$.

To examine this possibility, tensile testing was conducted on two different alloys: a Russian 01420 alloy with a composition of $\mathrm{Al}-5.5 \% \mathrm{Mg}-2.2 \% \mathrm{Li}-0.12 \% \mathrm{Zr}$ and a British Supral 100 Al-2004 alloy of Al-6\% Cu-0.4\% Zr [18]. Both of these alloys were subjected to processing by ECAP to a total of 12 passes using a die with a channel angle of $90^{\circ}$ with the first 8 passes at $673 \mathrm{~K}$ and then 4 additional passes at $473 \mathrm{~K}$. It can be shown from first principles that this processing introduces a total strain of $\sim 12$ in each sample [19]. For the $\mathrm{Al}-\mathrm{Mg}-\mathrm{Li}-\mathrm{Zr}$ alloy the initial grain size was $\sim 400 \mu \mathrm{m}$ and the grain size after ECAP processing was $\sim 1.2 \mu \mathrm{m}$ whereas for the $\mathrm{Al}-\mathrm{Cu}-\mathrm{Zr}$ alloy the grain size was reduced even further to $\sim 500 \mathrm{~nm}$.

Fig. 4 shows an example of the testing of the $\mathrm{Al}-\mathrm{Mg}-\mathrm{Li}-\mathrm{Zr}$ alloy after ECAP where the upper sample is untested and the two lower samples were pulled to failure at a testing temperature of $623 \mathrm{~K}$ using initial strain rates of $1.0 \times 10^{-2}$ and $1.0 \times 10^{-1} \mathrm{~s}^{-1}$. Both samples show examples of high strain rate superplasticity and the upper sample is not broken even after an elongation of $>1180 \%$. The uniform deformation within the gauge length, and thus the absence of necking, is consistent with the requirements for true superplastic flow [20]. Similar results were obtained also in the $\mathrm{Al}-\mathrm{Cu}-\mathrm{Zr}$ alloy with an elongation of $970 \%$ at an initial strain rate of $1.0 \times 10^{-2} \mathrm{~s}^{-1}$.

In superplastic flow, metals exhibit exceptionally high elongations but microstructural examinations after failure show that the grains remain essentially equiaxed and their final shapes do not follow the elongations of the samples. The retention of an equiaxed grain structure shows that flow occurs by grain boundary sliding in which the individual grains slide over each other during the deformation [21]. A simple consideration shows that the sliding will require an accommodation mechanism in order to prevent the opening of voids within the sample. This is most readily achieved through the occurrence of intragranular slip where dislocations move within the individual grains to accommodate the sliding process. This type of behavior is consistent with the conventional model for the occurrence of superplasticity by grain boundary sliding [22].

To check on the occurrence of intragranular slip during superplastic flow, experiments were conducted on a $\mathrm{Pb}-62 \% \mathrm{Sn}$ eutectic alloy where a sample was tested in tension under superplastic conditions at a temperature of $423 \mathrm{~K}$, marker lines were placed on the surface parallel to the tensile axis and then a series of photographs was recorded at the same positions on the sample surface for elongations from $50 \%$ to a total of $800 \%$ [23]. These photographs were then used to measure, using scanning electron microscopy, the intragranular dislocation strains (IS) at each elongation. Fig. 5 shows examples of these measurements as recorded within two different Sn phases.

For both grains it is apparent that IS is non-uniform, it tends to be oscillatory in nature and the overall contribution of IS to the total strain remains essentially zero. This means intragranular strain occurs within the grains in the manner depicted in Fig. 6 where slip takes place on different planes at different times.

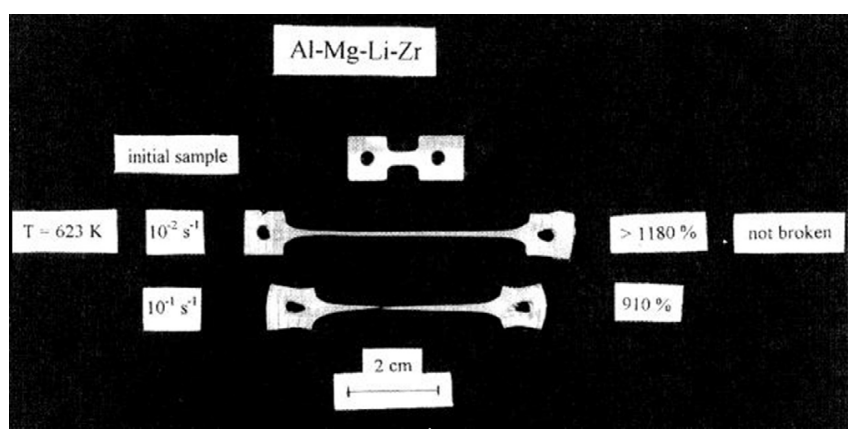

Fig. 4. A demonstration of high strain rate superplasticity in an $\mathrm{Al}-\mathrm{Mg}-\mathrm{Li}-\mathrm{Zr}$ alloy tested in tension at a temperature of $623 \mathrm{~K}$ using two different rapid strain rates [18].

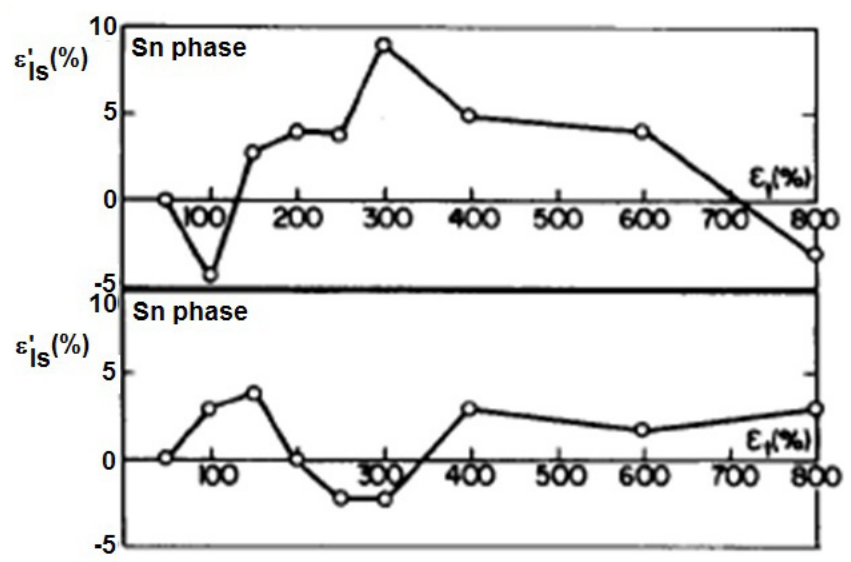

Fig. 5. Measurements of intragranular strains in two different $\mathrm{Sn}$ phases for elongations from $50 \%$ to $800 \%$ [23]. 


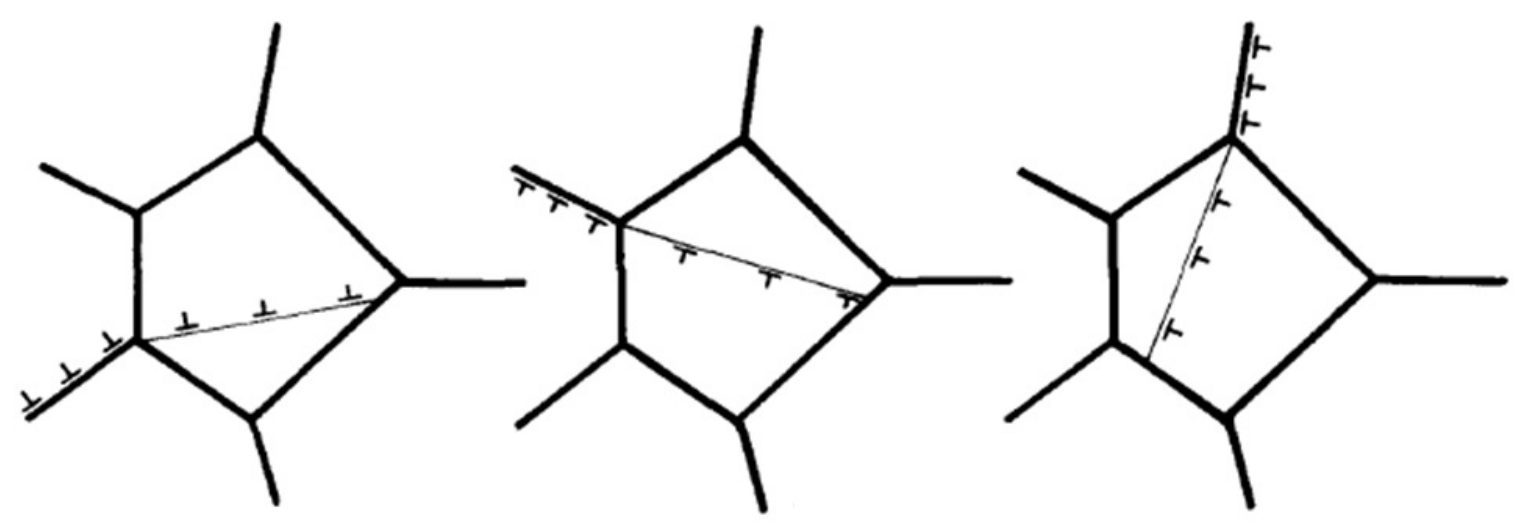

Fig. 6. The occurrence of intragranular strain within a grain during superplastic deformation at three similar, but different, increments of time [23].

\section{Summary and conclusions}

1. The establishment in Ufa in 1985 of the Institute for Metals Superplasticity Problems (IMSP) by Professor Oscar Kaibyshev led to a resurgence of interest in superplastic research and especially in the superplasticity that may be achieved in materials having ultrafine grain sizes.

2. The contributions to superplastic research over the last three decades by materials scientists in Ufa has been exceptional and examples are presented to demonstrate a small fraction of these achievements.

Acknowledgements. This work was supported by the European Research Council under ERC Grant Agreement No. 267464-SPDMETALS.

\section{References}

1. T. G. Langdon. J. Mater. Sci. 44, 5998 (2009).

2. C.E. Pearson. J. Inst. Metals. 54, 111 (1934).

3. E. E. Underwood. JOM. 14(12), 914 (1962).

4. A. J. Barnes. J. Mater. Eng. Perform. 16, 440 (2007).

5. M. M. I. Ahmed, T. G. Langdon. Metall. Trans. A. 8A, 1832 (1977).

6. T. G. Langdon. Mater. Sci. Forum. 838-839, 1 (2016).

7. Y. Ma, T. G. Langdon. Metall. Mater. Trans. A. 25A, 2309 (1994).
8. T. G. Langdon. Defect Diffusion Forum. 385, 3 (2018).

9. R.Z. Valiev, V.Yu. Gertsman, O.A. Kaibyshev. Phys. Status Solidi A. 97, 11 (1986).

10. T. G. Langdon. Metall. Trans. 13A, 689 (1982).

11. R.Z. Valiev, O.A. Kaibyshev, R.I. Kuznetsov, R.S. Musalimov, N. K. Tsenev. Dokl. Akad. Nauk SSSR 301, 864 (1988).

12. T. G. Langdon. Mater. Sci. Eng. A503, 6 (2009).

13. R.Z. Valiev, R.K. Islamgaliev, I. V. Alexandrov. Prog. Mater. Sci. 45, 103 (2000).

14. R.Z. Valiev, T.G. Langdon. Prog. Mater. Sci. 51, 881 (2006).

15. A.P. Zhilyaev, T.G. Langdon. Prog. Mater. Sci. 53, 893 (2008).

16. R.Z. Valiev, Y. Estrin, Z. Horita, T.G. Langdon, M. J. Zehetbauer, Y. T. Zhu. JOM. 58(4), 33 (2006).

17. R.Z. Valiev, Y. Estrin, Z. Horita, T.G. Langdon, M. J. Zehetbauer, Y. Zhu. JOM. 58, 1216 (2016).

18. R. Z. Valiev, D. A. Salimonenko, N. K. Tsenev, P. B. Berbon, T. G. Langdon. Scripta Mater. 37, 1945 (1997).

19. Y. Iwahashi, J. Wang, Z. Horita, M. Nemoto, T. G. Langdon. Scripta Mater. 35, 143 (1996).

20. T. G. Langdon. Metal Sci. 16, 175 (1982).

21. T. G. Langdon. Mater. Sci. Eng. A. 174, 225 (1994).

22. T. G. Langdon. Acta Metall. Mater. 42, 2437 (1994).

23. R. Z. Valiev, T. G. Langdon. Acta Metall. Mater. 41, 949 (1993). 